\title{
The Usefulness of CT Scanning in Diagnosing Dementia of the Alzheimer Type
}

\author{
J. Willmer, A. Carruthers, D.A. Guzman, B. Collins, J. Pogue and D.T. Stuss
}

\begin{abstract}
In order to determine the usefulness of Computerized Tomography (CT) scanning in making a diagnosis of dementia of the Alzheimer type, a group of patients diagnosed by NINCDS - ADRDA criteria $(n=22)$ were compared to a group of normal subjects $(n=49)$ using certain defined linear CT scan measurements. These measurements included specific measurements of the temporal lobes (temporal horns). Subjects were classified correctly $91.5 \%$ of the time with a high degree of probability. A diagnostic equation is presented which will allow testing of these methods in a prospective fashion.
\end{abstract}

RÉSUMÉ: Utilité du CT scan dans le diagnostic de la démence de type Alzheimer. Afín de déterminer l'utilité du CT scan dans le diagnostic de la démence de type Alzheimer, nous avons comparé un groupe de patients atteints de démence de type Alzheimer, telle que définie par les critères du NINCDS-ADRDA, à un groupe de sujets normaux, au moyen de certaines mesures linéaires tomodensitométriques bien définies. Ces mesures comprenaient des mesures spécifiques des lobes temporaux (cornes temporales). Les sujets étaient classifiés correctement $91.5 \%$ du temps, avec un haut degré de probabilité. Nous présentons une équation diagnostique qui permettra d'évaluer ces méthodes de façon prospective.

Can. J. Neurol. Sci. 1993; 20:210-216

To date the usefulness of Computerized Tomography (CT) scanning in the diagnosis of dementia has been limited. For the most part, CT scanning helps to diagnose the small number of patients with dementias characterized by specific structural lesions in the brain.' However, these disorders account for only $10-20 \%$ of the total cases of dementia. ${ }^{2}$ With the exception of some vascular lesions, CT is probably as useful as magnetic resonance imaging (MRI) in the workup of dementia. ${ }^{2.3}$ Dementia of the Alzheimer type (DAT) accounts for greater than fifty percent of cases. ${ }^{4.6}$ Not only is DAT the most prevalent of the disorders classified as the dementias, ${ }^{5}$ but it is also one of the most difficult to diagnose clinically.

The focus of most work on CT images has been on generalized cerebral atrophy. For some time the presence of such atrophy has been equated with the diagnosis of DAT, ${ }^{7}$ largely as a result of early supportive evidence from pathological studies. ${ }^{6}$ There are several problems in the use of generalized atrophy as a marker for DAT. Generalized atrophy is not unique to DAT, and can occur as a result of normal aging ${ }^{7.14}$ and results from different studies have been variable and inconsistent. ${ }^{10-13.15-23} \mathrm{CT}$-scan studies in DAT, other dementias, and normal aging suggest that there is enough overlap to prevent an accurate diagnosis of DAT by CT measurements of generalized cerebral atrophy. ${ }^{1.24-27}$

An alternative approach to evaluating CT changes in dementia is to examine changes in tissue density in the gray and white matter of the brain. Unlike cerebral atrophy, which was felt to reflect a general loss of neurons, changes in tissue density on CT might indicate histopathological changes within the neurons, ${ }^{28}$ the basis on which a pathological diagnosis of definite DAT is made. ${ }^{29.30}$ However, although some studies have suggested that various measures of tissue density on CT scan may discriminate patients with DAT from normals, ${ }^{28.31 .32}$ others have failed to demonstrate any difference in CT densities between demented patients and controls. ${ }^{12.33 .34}$

The failure of these methods to discriminate DAT from normal aging might be understood by the pathology of DAT. Although generalized cerebral atrophy and decreased tissue density are seen more frequently in the brains of deceased DAT patients, the neuropathological changes diagnostic of DAT occur more in a focal pattern than a generalized one. The temporal lobes, and more specifically those structures comprising the medial temporal lobes are the primary sites of the histopathological changes characteristic of.DAT. ${ }^{6.35-42}$ These structures play a major role in memory impairment which is one of the first and most consistent manifestations of DAT. ${ }^{43}$

Recent studies have achieved a diagnostic accuracy of greater than $80 \%$ when comparing patients with DAT to normal subjects using CT measurements of temporal lobe atrophy. $44-48$ Measurements of the temporal horns, Sylvian fissures, suprasellar cisterns and other medial temporal lobe structures appear able to

From the Elisabeth Bruyère Health Centre, Department of Medicine (Neurology), University of Ottawa (J.W., A.C., D.A.G.); Department of Psychology, Ottawa General Hospital (B.C.); Rotman Research Institute of Baycrest Centre for Geriatric Care (J.P., D.T.S.) and Division of Neurology and Department of Psychology, University of Toronto (D.T.S.)

Received November 24, 1992. Accepted March 26, 1993

Reprint requests to: Dr. J. Willmer, Elisabeth Bruyère Health Centre, 75 Bruyère Street, Ottawa, Ontario, Canada K 1N 5C8 
distinguish patients with DAT from normal subjects more accurately than measures involving other brain regions. The results of these studies support the hypothesis that medial temporal lobe atrophy on CT scan, like medial temporal lobe atrophy in pathological studies, is a better predictor of the presence of DAT than generalized atrophy.

This paper reports the results of a study to replicate these findings, to investigate simple diagnostic measurements that can be used in the early stages of DAT, and to correlate these measurements with neuropsychological scores.

\section{MeThOdology}

\section{SUBJECTS}

Two groups of subjects were defined.

\section{Probable Dementia of the Alzheimer Type (DAT) $(\mathbf{N}=22)$}

These patients had been referred to the Memory Disorder Clinic at the Ottawa General Hospital by their primary-care physicians because of memory dysfunction. They underwent the following assessments: complete medical and neurological examination, including a mental status assessment; EEG; CT scan; psychiatric examination; family, social, and medical history; and neurobehavioural examination.

The neurobehavioural examination yielded the following neuropsychological variables: Mini-mental State ${ }^{49}$ - total score, the Dementia Rating Scale ${ }^{50}$ - total score, subscales of attention, initiation; memory, construction, and conceptualization, and a modified version of the Boston Naming Test ${ }^{51}$ - total score correct.

Diagnoses were based on the NINCDS-ADRDA 52 criteria. The same diagnosis had to be reached independently by two physicians and confirmed at a $9-12$ month follow-up before the subject was included in the study. Overall agreement between them in all subjects assessed was $85 \%$.

Subjects were excluded if a consistent diagnosis could not be made, or if the subject clearly fell into a diagnostic category other than Alzheimer's disease (e.g., multi-infarct dementia, Parkinson's disease). In addition, patients who might have dementia of the frontal type, ${ }^{53.54}$ but who would fit within the general criteria of probable DAT were excluded.

\section{Normal Control Subjects}

A control group composed of 49 elderly normal subjects was recruited from individuals living independently in the community. These subjects were thoroughly screened by medical history and examination, neurological examination, and neuropsychological assessment. Exclusion criteria for this group included a history of alcohol or drug abuse, or a history of previous neurological or psychiatric illness. All scored greater than 25 on the MiniMental State Exam.

The demographic variables of these two groups are presented in Table 1. There are no significant differences between the two groups for age and education.

\section{Dependent Measurements}

All patients referred to the clinic received a CT scan carried out on a GE CT 9800 scanner using a positive 20 degree slice angle in relation to the canthomeatal line to get better visualization of the temporal lobes and the temporal horns. ${ }^{17} \mathrm{~A}$ series of cuts five millimetres thick spaced at five millimetre intervals was obtained, extending from the cranial floor to the first cut which did not contain any portion of the lateral ventricles. Three slices were chosen for measurements (Figure 1). Slice 1 was chosen as that showing the widest cross section of the temporal horns, slice 2 showed the widest spacing of the frontal horns and slice 3 showed the greatest measurement of the lateral ventricular waist. Six CT scan measurements were operationally defined.

Temporal Horns (TH):

The sums of the diameters of the left and right temporal horns measured perpendicularly to the longest axis seen on the CT slice at the widest point.

Bifrontal (BF):

The widest point between the lateral extremes of the left and right frontal horns.

Bicaudate $(\mathrm{BC})$ :

The widest distance between the caudate nuclei at their midpoints.

Third Ventricle (TV):

The widest point measured horizontally.

Table 1. Demographic Variables of the Two Groups

\section{DIAGNOSTIC}

CLASSIFICATIONS
VARIABLES

EDUCATION"

\section{SEVERITYc}

\begin{tabular}{|c|c|c|c|c|c|c|c|c|c|c|c|c|c|}
\hline & $\mathrm{N}^{\mathrm{d}}$ & $\mathbf{M}$ & $\mathrm{SD}$ & RNG & $\mathbf{M}$ & $\mathrm{SD}$ & RNG & $\mathrm{M}$ & $\mathrm{SD}$ & RNG & $\mathbf{M}$ & SD & RNG \\
\hline Probable DAT & 22.00 & 72.00 & 7.00 & $56-84$ & 2.70 & 0.72 & $1-4$ & 2.60 & 2.40 & $0-10$ & 13.10 & 6.20 & $0-23$ \\
\hline Normal Control & 49.00 & 71.00 & 8.10 & $57-87$ & 2.60 & 0.77 & $1-4$ & $\mathrm{NA}$ & NA & NA & 29.20 & 0.90 & $26-30$ \\
\hline
\end{tabular}

aducation was divided into four categories: $1=$ to grade 8 or less; $2=$ to grade 12 or $13 ; 3=$ undergraduate university or college; 4 = graduate degree.

${ }^{b}$ Duration refers to the number of years the subjective complaints or documented deficits had been noted.

c Severity is expressed by the score on the MMSE.

d $\mathrm{N}=$ Number; $\mathrm{M}=$ Mean; $\mathrm{SD}=$ Standard Deviation; RNG = Range. 


\section{Sylvian Fissures (SF):}

The sums of the left and right posterior sylvian fissure widths measured at their widest points.

\section{Lateral Ventricle (LV):}

The greatest span of the lateral ventricles at their midpoints.

All measurements were expressed as ratios of the internal skull diameter (from inner table to inner table) measured horizontally at the same level as the measurement.

\section{Statistical Procedure}

The discriminant function analysis was designed to test if the $\mathrm{CT}$ measurements were independently beneficial in differentiating between the patients with probable DAT and normal subjects.

Discriminant analyses were used to build models predicting diagnostic group membership. All models or classification criteria were developed starting with all six defined CT scan indices: $\mathrm{BF}, \mathrm{BC}, \mathrm{LV}, \mathrm{TV}, \mathrm{TH}$, and SF. The resulting classification criteria are a series of equations known as the linear discriminant function. The relative contribution of each CT scan index was identified using the correlation between the raw scores and the predicted value from the linear discriminant function ${ }^{55}$ with all $\mathrm{CT}$ scan indices in the model. This procedure enabled identification of the model that would best differentiate the two groups. In addition to group discrimination, the number of subjects correctly and incorrectly classified according to these equations, and the probability for each subject, on the basis of the CT measurements, belonging to the group in which they were classified were determined. Further, the procedure indicated the relative value of each CT measurement in differentiating the two groups. Correlations were completed between the behavioural and CT indices.

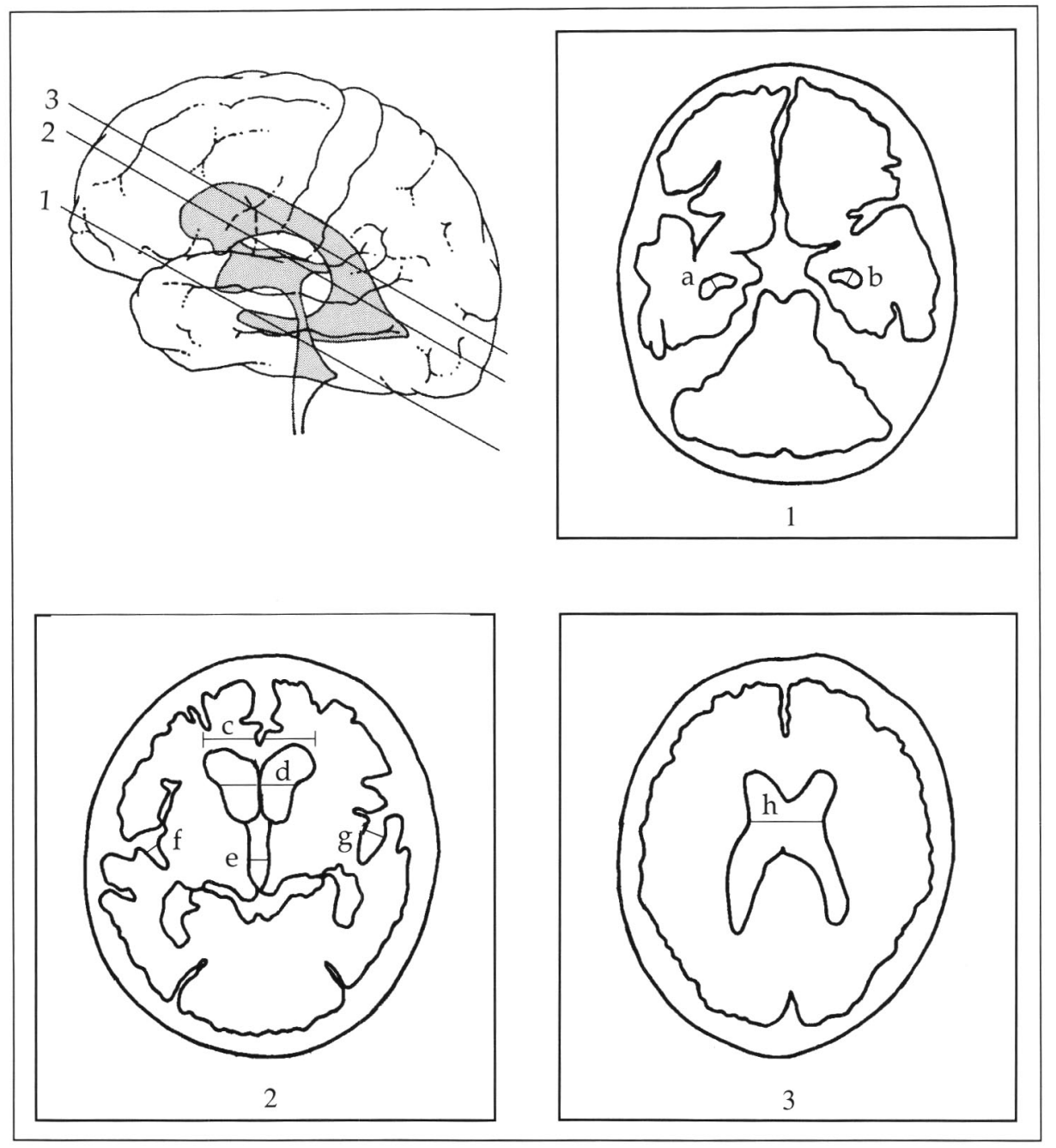

Figure I - This figure schematically identifies the angle of the CT scan, and the operational measurements at the defined $C T$ scan slice.

$a+b=T H$ - temporal horn diameters bilaterally

$c=B F-$ bifrontal span

$d=B C$ - bicaudate span

$e=T V-$ third ventricle

$f+g=S F-$ sylvian fissure width bilaterally

$h=L V$-lateral ventricle 


\section{ReSULTS}

When the probable DAT patients were compared to the normal control group, using all six CT scan variables, a significant difference between the groups was found $[F(6,64)=18.8$, $\mathrm{p}<.0001]$. In the initial analysis, all six variables were significant in contributing to the discrimination between the two groups. The correlation between the raw scores and the predicted value from the first linear discriminant function ranged from .81 (TH) to .36 (SF). All except SF correlated at or above .70. The classification analysis assesses how well the dependent measurements, in this case the defined CT measurements, predict whether an individual has Alzheimer's disease or not, as diagnosed by the defined clinical criteria. The same high level of correct classification was achieved when only three variables were used: TH, BC and LV. The overall classification of subjects into their proper diagnostic group using all CT scan measurements was $91.5 \%$, with three individuals from each group being misclassified. The normals were correctly classified at $94 \%$, the patients at $86 \%$ (see Table 2). That is, using the CT scan measurements alone, one can predict whether a person has Alzheimer's disease or not with approximately $91 \%$ accuracy. The TH measurement, reflecting the sums of the diameters of the left and right temporal horns, contributed the most to differentiation of the two groups. The classification functions are provided to allow establishment of diagnostic predictions to test the algorithm in a prospective manner. A predictive algorithm can be derived from the classification functions as follows. Two values, $\mathrm{A}$ and $\mathrm{N}$ are determined $(\mathrm{A}=(-6.6) \mathrm{TH}+(235.19) \mathrm{BC}+(88.94)$ LV-41.9I; $\mathrm{N}=(-81.54) \mathrm{TH}+(208.98) \mathrm{BC}+(51.46) \mathrm{LV}-24.99) . \mathrm{A}$ diagnosis of DAT is predicted when $A$ is greater than $N$. Standardized Canonical coefficients transfer the value of each measurement onto a similar scale by scaling each coefficient over the pooled within group variances. Subsequently, the relative importance of each CT scan index with regard to differentiating the diagnostic groups can be directly compared (see Table 2).

In using any measurement to make a diagnosis, the confidence in the diagnosis is important. In a discriminant function analysis, this is identified by the probability of being placed in the appropriate group based on the dependent measurements. Figure 2 illustrates that, of those correctly classified, the majority of subjects are classified correctly in their appropriate group with a high degree of probability.

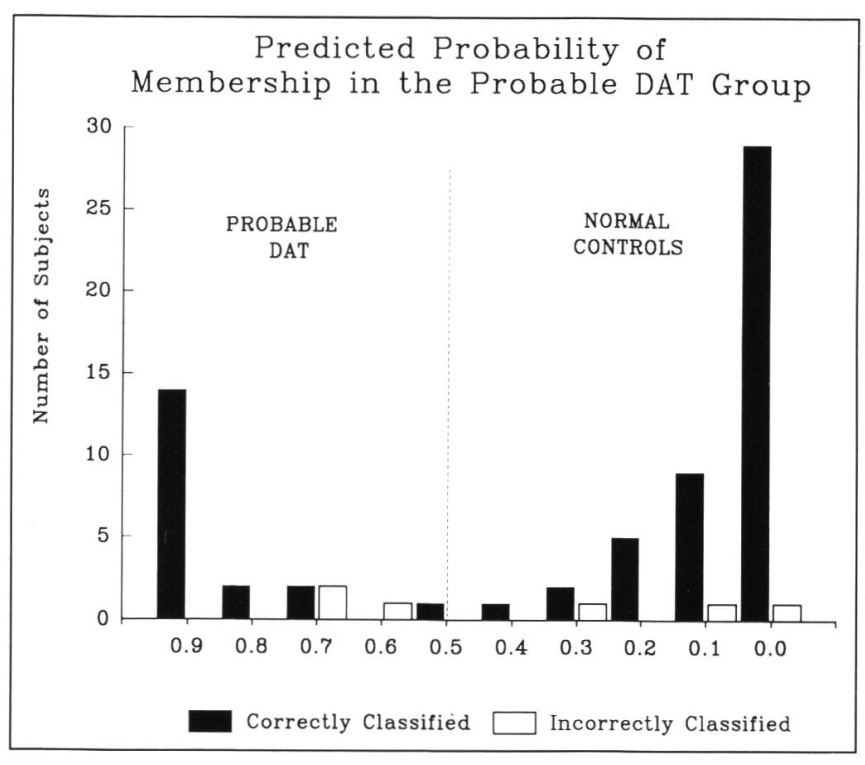

Figure 2 - This figure illustrates the probability of group membership for correct classification of probable DAT patiens and elderly normal control subjects into their proper group based on the CT scan measurements. In general, the confidence that can be placed in the diagnosis is high, with most subjects in each group being correctly classified with a high degree of probability. The probability scale refers to each subject's overall probability as being classified as having Alzheimer's disease or not. On the right of the figure $(0.5$. 0.0 ) lie the control subjects (in black) actually classified as not having DAT. The majority of these individuals had virmally no chance of being misdiagnosed $(0.0 \%$ probability). On the left side are those DAT patients correctly identified by CT scan as having DAT, the majority again being correctly classified at $90-100 \%$ probability of correct diagnosis. Three "normal" subjects were classified as having $C T$ scans similar to the DAT patients, the probabilities ranging at 60 ". 70\%. For the three misclassified DAT patients, the probabilities that their CT scan measurements would not be considered comparable to the correctly classified DAT patients is $0-30 \%$.

Table 2. Accuracy of Classification, Classification Functions, and Standard Co-efficients for the Discriminant Function Analysis of the Probably DAT vs Normal

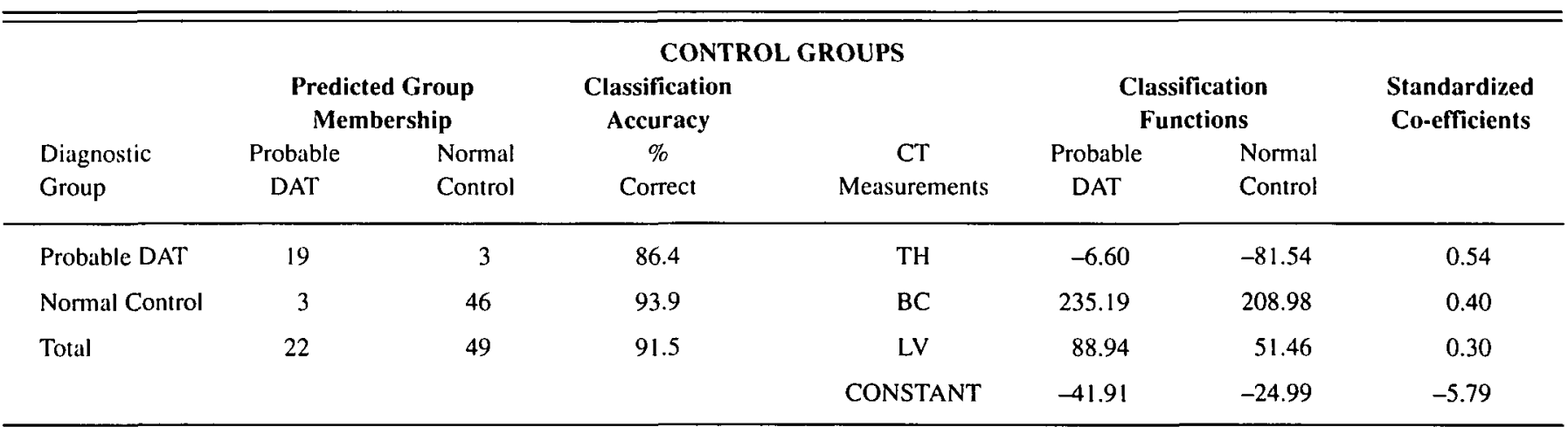


Table 3. Median Scores and Range on Additional Variables for Those Alzheimer Patients Correctly and Incorrectly Classified Based on CT Scan

\begin{tabular}{|c|c|c|c|c|c|c|}
\hline $\mathrm{DRS}^{\mathrm{b}}$ & 19 & 94 & $62-113$ & 3 & 115 & $100-115$ \\
\hline $\mathrm{BDS}^{\mathrm{c}}$ & 15 & 4 & $0-9$ & 2 & 5 & $4-6$ \\
\hline Age & 19 & 73 & $56-84$ & 3 & 70 & $64-80$ \\
\hline Age of Onset & 19 & 70 & $54-82$ & 3 & 70 & $63-80$ \\
\hline Duration & 19 & 3 & $0-10$ & 3 & 0 & $0-1$ \\
\hline
\end{tabular}

Mini-Mental State Examination

'Mattis Dementia Rating Scale

${ }^{'}$ Beck Depression Scale

We examined if there were any obvious patterns as this might explain the errors in the classification; e.g., if only the most severe patients (categorized on the basis of the MMSE and DRS scores) were classified correctly. Table 3 identifies the median score and range of the major demographic and psychological variables for those Alzheimer's patients correctly and incorrectly identified on the basis of the CT scan measurements. These limited data suggest that there may be no relationship with psychological measures of dementia (MMSE, DRS), scores on the Beck Depression Scale and the basic variables of education, age, or age of onset of the disease. It appears, however, that those incorrectly identified are more likely to have been diagnosed as having DAT for a much shorter period.

Only the Mini-mental Status Test was administered to both the probable DAT patients and the control group. Correlations between this global measure and the six CT scan measures, all exceeded a probability of .001 , the correlates ranging from -.70 (BC) to -.42 (SF). The second highest correlation was -.65 for LV. Within the probable DAT group, there were interesting specific correlations. The overall Mattis score correlated with $\mathrm{TH}(\mathrm{r}=-.51, \mathrm{p}=0.01)$ and BF $(\mathrm{r}=-.45, \mathrm{p}=0.04)$. The memory score of the Mattis correlated significantly with $\mathrm{TH}(r=-.44$, $p=0.04)$. Three different measures correlated with the attention subtest: $\operatorname{LV}(r=-.50, p=0.02) ; \mathrm{TV}(r=-.58, p=0.005) ; \mathrm{SF}(r=-.51$, $p=0.01)$. Only TV $(r=-.49, p=0.02)$ correlated with the construction score. The initiation and conceptualization subscores did not correlate significantly with any of the CT scan measures.

\section{DiSCUSSION}

CT scanning provided a highly significant discrimination of patients with the diagnosis of DAT. This was possible because the images were analyzed, based on the neuropathology, from the perspective of the temporal lobe structures. Although the lateral ventricular measurement (LV) may only reflect generalized atrophy, the temporal horn measurement (TH) reflects specific temporal lobe atrophy and the bicaudate measurement $(\mathrm{BC})$ may reflect anterior temporal lobe atrophy. The overall diagnostic accuracy achieved was $91.5 \%$ when comparing normal subjects to individuals with probable DAT. Two factors are important: the groups were differentiated at a high level of diagnostic accuracy; the overall probability of correct classification into the appropriate group was high. It is unlikely that the comparison is of two groups that were premorbidly different. Patients were matched as closely as possible, and there were no significant differences in age or years of education.

A factor in the high degree of accuracy obtained may be related to the fact that the CT scan measurements were based on an application of the neuropathology of DAT and the relationship to the anatomy of the temporal lobe structures. The first step in undertaking the study was to choose a measure of temporal lobe atrophy. Because of their proximity to the structures of the medial temporal lobe, the temporal horns of the lateral ventricles would seem worthwhile to focus attention on. They have been noted to widen not just at the tips, but also posteriorly as a result of atrophic changes in the temporal lobe white matter and the hippocampus. ${ }^{47}$ The temporal horns are not often widened as a result of normal aging, ${ }^{46.47}$ as opposed to other indicators of temporal lobe atrophy such as suprasellar cistern width. As the temporal horn appears to enlarge uniformly, linear measures are likely to give as good results as area or volume measurements. They also have the advantage of being simpler, less costly and hence more clinically applicable.

To properly visualize the temporal horns, proper CT scan technique is essential. In the literature, a number of different approaches have been described but two stand out as being most useful. George et al. ${ }^{45}$ used a scan angle of $-20^{\circ}$ to the canthomeatal line to cut the temporal lobe and temporal horns longitudinally and allow excellent visualization of medial temporal lobe structures. A scan angle of $+20^{\circ}$ to the canthomeatal line as described by Albert et al. ${ }^{17}$ allows one to look at a cross section of the temporal horn. Since this is relatively easy to measure, we used this technique.

It is quite clear that the greater part of the pathology in DAT is in the temporal lobes and more specifically in their medial structures. It is thus not surprising that CT scan measurements of these regions are useful in delineating patients with DAT from normal subjects. As diagnostic groups are determined by clinical criteria, meaningful comparisons are difficult because there is not $100 \%$ correlation between these criteria and autopsy 
diagnosis. Furthermore, a small portion cannot even be reliably diagnosed by autopsy. The use of control groups taken from patients referred to a memory disorder clinic, and diagnosed as normal, is also somewhat questionable, as a number of these subjects may eventually go on to develop dementia. The problem lies in the sensitivity of our testing procedures.

The apparent high degree of accuracy in this study may reflect a potential weakness of the study. The fact that highly selected groups were used, both with respect to the patients with DAT and the normal controls, may have significantly inflated the classification accuracy. Assistance with diagnosis is most crucial early in the course of the disease, when clinical findings may be equivocal. The discriminative power of the classification equation should be tested on an independent sample.

An important follow up to this study will be to track the progress of the subjects that were misclassified, and to use the discriminant function algorithm in a predictive manner. An extension of this study using a larger population may answer some of the questions posed, such as the relationship of the diagnostic groups and their severity to psychological scores and demographics and whether the results are applicable to any age group. In the present study, attempts to divide the subjects into those less than and greater than 65 years of age for analysis were unsuccessful due to small numbers $(n=9)$ in the former group. Autopsy confirmation of at least some of this group will be neccessary to refine our diagnostic algorithm.

Although global scores of cognitive function did correlate well with measures of atrophy on CT scan, one of the highest specific correlations was between the measures of the temporal horn and memory function. This finding is expected, as the temporal lobes subserve memory function and the bulk of the pathology in DAT is found here. Memory loss is also the earliest and most consistent manifestation of DAT. Unfortunately, the sample size was too small to draw many specific conclusions about the correlations between radiological measurements and cognitive function. The findings do suggest that a larger study may demonstrate a relationship between these variables.

This study emphasizes the important role CT scanning can play in the diagnosis of DAT. It may be said that as we used clinical assessment as our validity criterion, clinical assessment is all that is needed to make the most accurate diagnosis. The clinical assessment employed in this study was stringent and required validation by two neurologists experienced in the diagnosis of dementia. This type of assessment is itself costly and is not readily available in all centres, although is currently accepted as the standard diagnostic approach excluding routine CT scanning. ${ }^{56}$ The correlation of CT scan findings with this type of clinical assessment will allow a more accurate diagnosis to be achieved in those centres with limited experience and expertise.

The CT scanner is becoming readily available, even in smaller centres. The measurement technique employed is simple and replicable, so that physicians without benefit of expert neuroradiological expertise could make a diagnostic prediction based on the algorithm presented. This diagnosis would be reliable and reproducible. The procedure will aid in the diagnosis and minimize the possibility of missing other disorders. It is not suggested that all patients with dementia have a CT scan but that it may be helpful in early cases and those with an atypical clinical picture.

Although many feel that accurate diagnosis is not of vital importance in irreversible dementias, except as an academic exercise, we feel that this view has to change. With the advent of possible therapies for DAT, accurate diagnosis will be essential to interpret the results of therapeutic trials. Until specific biochemical markers are identified, we feel that the CT scanner can be a useful, reliable and cost-effective tool in the diagnosis of dementia, and in following its course.

\section{ACKNOWLEDGEMENTS}

Funding for the involvement of D. Stuss and J. Pogue was obtained from an Ontario Mental Health Foundation research grant to D. Stuss. R. Brebner prepared the medical illustrations. The authors would like 10 thank Drs. T. Picton and R. Nelson for reviewing the manuscript, Dr. Z. Grahovac for neuroradiological assistance and $C$. MacKellar for preparing and verifying the bibliography.

\section{REFERENCES}

1. Benson DF. Neuroimaging and dementia. Neurol Clin 1986; 4(2): 341-353.

2. Bradshaw JR, Thomson JL, Campbell MJ. Computed tomography in the investigation of dementia. Br Med J (Clin Res Ed) 1983; 286(6361): $277-280$.

3. Jagust WJ, Eberling JL. MRI, CT, SPECT, PET: their use in diagnosing dementia. Geriatrics 1991 Feb; 46(2): 28-35.

4. Petrie WM. Alzheimer's disease. Compr Ther 1985; 11(7): 38-43.

5. Katzman R. Clinical presentation of the course of Alzheimer's disease: the atypical patient. Interdisciplin Top Gerontol 1985: 20: 12-18.

6. Tomlinson BE, Blessed G, Roth M. Observations on the brains of demented old people. J Neurol Sci 1970; 1I(3): 205-242.

7. Huckman MS, Fox J, Topel J. The validity of criteria for the evaluation of cerebral atrophy by computed tomography. Radiology 1975; 116(1): 85-92.

8. Tomlinson BE. Blessed G, Roth M. Observations on the brains of non-demented old people. J Neurol Sci 1968; 7(2): 331-356.

9. Laffey PA, Peyster RG, Nathan R, Haskin ME, McGinley JA. Computed tomography and aging: results in a normal elderly population. Neuroradiology $1984 ; 26(4)$ : $273-278$.

10. Ford CV, Winter J. Computerized axial tomograms and dementia in elderly patients. J Gerontol 1981: 36(2): 164-169.

11. Hughes CP, Gado M. Computed tomography and aging of the brain. Radiology 1981; 139(2): 391-396.

12. Gado M, Hughes CP, Danziger W, Chi D. Aging, dementia, and brain atrophy: a longitudinal computed tomographic study. Am J Neuroradiol 1983; 4(3): 699-702.

13. George AE, de Leon MJ, Rosenbloom S, Ferris SH, Gentes C, et al Ventricular volume and cognitive deficit: a computed tomographic study. Radiology 1983; 149(2): 493-498.

14. Roberts MA, Caird FI, Grossart KW, Steven JL. Computerized tomography in the diagnosis of cerebral atrophy. J Neurol Neurosurg Psychiatry 1976; 39(9): 909-915.

15. McGeer PL. Brain imaging in Alzheimer's disease. Br Med Bull 1986; 42(1): 24-28.

16. de Leon MJ, George AE, Reisberg B, Ferris SH, Kluger A, et al. Alzheimer's disease: longitudinal CT studies of ventricular change. Am J Radiol 1989; 152(6): 1257-1262.

17. Albert M, Naeser MA, Levine HL, Garvey AJ. Ventricular size in patients with presenile dementia of the Alzheimer's type. Arch Neurol 1984; 41(12): 1258-1263.

18. Arai H, Kobayashi K, Ikeda K, Nagao Y, Ogihara R, el al. A computed tomography study of Alzheimer's disease. J Neurol 1983; 229(2): 69-77.

19. Gado M, Hughes CP, Danziger W, Chi D, Jost G, et al. Volumetric measurements of the cerebrospinal fluid spaces in demented subjects and controls. Radiology 1982; 144(3): 535-538.

20. Brinkman SD, Sarwar M, Levin HS, Morris HH. Quantitative indexes of computed tomography in dementia and normal aging. Radiology 1981; 138(1): 89-92.

21. Jacoby RJ, Levy R. Computed tomography in the elderly. 2. Senile dementia: diagnosis and functional impairment. Br J Psychiatry 1980; 136: 256-269. 
22. Drayer BP, Heyman A, Wilkinson W; Barrett L, Weinberg T. Earlyonset Alzheimer's disease: an analysis of CT findings. Ann Neurol 1985; 17(4): 407-410.

23. Creasey H, Schwartz M, Frederickson H, Haxby JV, Rapoport SI. Quantitative computed tomography in dementia of the Alzheimer type. Neurology 1986; 36(12): 1563-1568.

24. Luxenberg JS, Friedland RP, Rapoport SI. Quantitative X-ray computed tomography (CT) in dementia of the Alzheimer type (DAT). Can J Neurol Sci 1986; 13(4 Suppl): 570-572.

25. Damasio H, Eslinger $P$, Damasio AR, Rizzo M, Huang HK, et al. Quantitative computed tomographic analysis in the diagnosis of dementia. Arch Neurol 1983; 40(12): 715-719.

26. Erkinjuntti T. Differential diagnosis between Alzheimer's disease and vascular dementia: evaluation of common clinical methods. Acta Neurol Scand 1987; 76(6): 433-442.

27. Erkinjuntti T, Ketonen L, Sulkava R, Vuorialho M, Palo J. CT in the differential diagnosis between Alzheimer's disease and vascular dementia. Acta Neurol Scand 1987; 75(4): 262-270.

28. George AE, de Leon MJ, Ferris SH, Kricheff II. Parenchymal CT correlates of senile dementia (Alzheimer disease): loss of graywhite matter discriminability. Am J Neuroradiol 1981; 2(3): 205213.

29. Kemper T. Neuroanatomical and neuropathological changes in normal aging and dementia. In: Albert M, ed. Clinical Neurology of Aging. New York: Oxford University Press 1984; 9-52.

30. Tierney MC. Fisher RH, Lewis AJ, Zorzitto ML, Snow WG, et al. The NINCDS-ADRDA Work Group criteria for the clinical diagnosis of probable Alzheimer's disease: a clinicopathologic study of 57 cases. Neurology 1988; 38(3): 359-364.

31. Naeser MA, Gebhardt C, Levine HL. Decreased computerized tomography numbers in patients with presenile dementia. Detection in patients with otherwise normal scans. Arch Neurol 1980; 37(7): 401-409.

32. Bondareff W, Baldy R, Levy R. Quantitative computed tomography in senile dementia. Arch Gen Psychiatry 1981; 38(12): 1365-1368.

33. Colgan J Naguib M, Levy R. Computed tomographic density numbers. A comparative study of patients with senile dementia and normal elderly controls. Br J Psychiatry 1986; 149: 716-719.

34. Wilson RS, Fox JH, Huckman MS, Bacon LD, Lobick JJ. Computed tomography in dementia. Neurology 1982; 32(9): 1054-1057.

35. LeMay M, Stafford JL, Sandor T, Albert M, Haykal H, et al. Statistical assessment of perceptual CT scan ratings in patients with Alzheimer type dementia. J Comput Assist Tomogr 1986; 10(5): 802-809.

36. Wilcock GK. The temporal lobe in dementia of Alzheimer's type. Gerontology 1983; 29(5): 320-324.

37. Wilcock GK, Esiri MM. Plaques, tangles and dementia. A quantitative study. J Neurol Sci 1982; 56(2-3): 343-356.

38. Ball MJ. Neuronal loss, neurofibrillary tangles and granulovacuolar degeneration in the hippocampus with ageing and dementia. A quantitative study. Acta Neuropathol (Berl) 1977; 37(2): 11 1-118.
39. Ball MJ, Lo P. Granulovacuolar degeneration in the ageing brain and in dementia. J Neuropathol Exp Neurol 1977; 36(3): 474-487.

40. Hyman BT, Van Horsen GW, Damasio AR, Barnes CL. Alzheimer's disease: cell-specific pathology isolates the hippocampal formation. Science 1984; 225(4667): 1168-1170.

41. Hyman BT, Van Hoesen GW, Kromer LJ, Damasio AR. Perforant pathway changes and the memory impairment of Alzheimer's disease. Ann Neurol 1986; 20(4): 472-481.

42. Herzog AG, Kemper TL. Amygdaloid changes in aging and dementia. Arch Neurol 1980; 37(10): 625-629.

43. Corsellis J. The limbic areas in Alzheimer's disease and in other conditions associated with dementia. In: Wolstenholme G, O'Connor M, eds. Alzhemier's Disease and Related Conditions. London: J\&A Churchill 1970; 37-45.

44. LeMay M, Alvarez $N$. The relationship between enlargement of the temporal horns of the lateral ventricles and dementia in aging patients with Down syndrome. Neuroradiology 1990; 32(2): 104-107.

45. George AE, de Leon MJ, Stylopoulos LA, Miller J, Kluger A, et al. $C T$ diagnostic features of Alzheimer disease: importance of the choroidal/hippocampal fissure complex. Am J Neuroradiol 1990; 11(1): 101-107.

46. Kido DK, Caine ED, LeMay M, Ekholm S, Booth $\mathrm{H}$, et al. Temporal lobe atrophy in patients with Alzheimer disease: a CT study. Am J Neuroradiol 1989; 10(3): 55I-555.

47. LeMay M. CT changes in dementing diseases: a review. Am J Radiol 1986; 147(5): 963-975.

48. Sandor T, Albert M, Stafford J, Harpley S. Use of computerized CT analysis to discriminate between Alzheimer patients and normal control subjects. Am J Neuroradiol 1988; 9(6): 1181-1187.

49. Folstein MF, Folstein SE, McHugh PR. "Mini-mental state": a practical method for grading the cognitive state of patients for the clinician. J Psychiatr Res 1975; 12(3): 189-198.

50. Mattis $\mathrm{S}$. Mental status examination for organic mental syndrome in the elderly patient. In: Bellak L, Karasu TB, eds. Geriatric Psychiatry. New York, Grune \& Stratton 1976.

51. Kaplan E, Goodglass H, Weintraub S. The Boston Naming Test. Philadelphia, PA: Lea \& Febiger 1983.

52. McKhann G, Drachman D, Folstein M, Katzman R, Price D, et al. Clinical diagnosis of Alzheimer's disease: report of the NINCDS-ADRDA Work Group under the auspices of Department of Health and Human Services Task Force on Alzheimer's Disease. Neurology 1984; 34(7): 939-944.

53. Neary D, Snowden JS, Northen B, Goulding P. Dementia of frontal lobe type. J Neurol Neurosurg Psychiatry 1988; 51(3): 353-361.

54. Neary D. Dementia of frontal lobe type. J Am Geriatr Soc 1990; 38(1): $71-72$.

55. Huberty CJ. Lssues in the use and interpretation of discriminant analysis. Psychol Bull 1984; 95(1): 156-171.

56. Varga M, Wortzman G, Freedman M. Assessment of cognitive impairment: the role of CT. Can J Neurol Sci 1991; 18(2): 129131. 